\title{
Inter-laboratory comparison of three different real-time PCR assays for the detection of Pneumocystis jiroveci in bronchoalveolar lavage fluid samples
}

\author{
Catharina F. M. Linssen, ${ }^{1}$ Jan A. Jacobs, ${ }^{1}$ Pieter Beckers, ${ }^{2}$ \\ Kate E. Templeton, ${ }^{3}$ Judith Bakkers, ${ }^{2}$ Ed J. Kuijper, ${ }^{3}$ Willem J. G. Melchers, ${ }^{2}$ \\ Marjolein Drent ${ }^{4}$ and Cornelis Vink ${ }^{1}$ \\ ${ }^{1}$ Department of Medical Microbiology, Maastricht Infection Center (MINC), University Hospital \\ Maastricht, PO Box 5800, 6202 AZ Maastricht, The Netherlands \\ ${ }^{2}$ Department of Medical Microbiology, Radboud University Nijmegen Medical Centre (RUNMC), \\ PO Box 9101, 6500 HB Nijmegen, The Netherlands \\ ${ }^{3}$ Department of Medical Microbiology, Leiden University Medical Center (LUMC), PO Box \\ 9600, 2300 RC Leiden, The Netherlands \\ ${ }^{4}$ Department of Respiratory Medicine, University Hospital Maastricht, PO Box 5800, 6202 AZ \\ Maastricht, The Netherlands
}

Correspondence

Catharina F. M. Linssen

klin@lmib.azm.nl

Received 3 February 2006

Accepted 15 June 2006

\begin{abstract}
Pneumocystis jiroveci pneumonia (PCP) is an opportunistic infection affecting immunocompromised patients. While conventional diagnosis of PCP by microscopy is cumbersome, the use of PCR to diagnose PCP has great potential. Nevertheless, inter-laboratory validation and standardization of PCR assays is lacking. The aim of this study was to evaluate the inter-laboratory agreement of three independently developed real-time PCR assays for the detection of $P$. jiroveci in bronchoalveolar lavage fluid samples. Therefore, 124 samples were collected in three tertiary care laboratories (Leiden University Medical Center, Maastricht Infection Center and Radboud University Nijmegen Medical Centre) and were tested by both microscopy and real-time PCR. Of 41 samples positive for $P$. jiroveci by microscopy, 40 were positive in all three PCR assays. The remaining sample was positive in a single assay only. Out of 83 microscopy-negative samples, 69 were negative in all three PCR assays. The other 14 samples were found positive, either in all three assays $(n=5)$, in two $(n=2)$ or in one of the assays $(n=7)$. The data demonstrate high inter-laboratory agreement among real-time PCR assays for the detection of $P$. jiroveci.
\end{abstract}

\section{INTRODUCTION}

Pneumocystis carinii is an opportunistic pathogen that was classified as a fungus in 1988 (Edman et al., 1988). Although human-derived $P$. carinii ( $P$. carinii f. sp. hominis) has recently been renamed Pneumocystis jiroveci, the abbreviation PCP (now referring to Pneumocystis pneumonia) remains in use (Stringer et al., 2001). Patients at risk for $P$. jiroveci pneumonia can be divided into two categories: HIV positive and HIV negative. Several risk factors have been identified in the HIV-negative group, such as immunosuppressive medication, or an inherited or acquired immunodeficiency (Kovacs et al., 2001). Since untreated PCP is

\footnotetext{
Abbreviations: BAL, bronchoalveolar lavage; DHPS, dihydroperoate synthase; LUMC, Leiden University Medical Center; MINC, Maastricht Infection Center; MSG, major surface glycoprotein; PCP, Pneumocystis jiroveci pneumonia; RUNMC, Radboud University Nijmegen Medical Centre.
}

associated with a high morbidity and mortality (Sepkowitz, 2002; Yale \& Limper, 1996), especially in HIV-negative patients, a rapid and reliable diagnosis is mandatory. Current diagnosis of PCP relies on tinctorial and/or immunofluorescent staining of induced sputum or bronchoalveolar lavage (BAL) fluid samples (Djamin et al., 1998; Thomas \& Limper, 2004). Using these methods, sensitivity and specificity rates are reached which exceed $95 \%$ (Amin et al., 1992; Chandra et al., 1988; Elvin et al., 1988; Kovacs et al., 2001). Major drawbacks of microscopy, however, are that it is cumbersome and requires trained microscopists. The latter makes it essential that positive samples are encountered regularly in order to maintain an expertise in microscopy. In recent years, the incidence of PCP has declined significantly, especially in HIV-positive patients. Due to the introduction of highly active anti-retroviral therapy, PCP chemoprophylaxis, and an increase of patients receiving chemotherapy, the future trend will be towards 
samples with relatively low $P$. jiroveci burdens, making the diagnosis of PCP even more difficult (Limper et al., 1989; Miller, 1999). Therefore, a rapid diagnostic technique which can identify the presence of a low number of cysts is needed.

Nucleic acid amplification tests, such as PCR, play an increasing role in the detection of $P$. jiroveci (Larsen et al., 2002b; Wakefield et al., 1990). In particular, real-time PCR is highly suitable for the diagnosis of PCP, since this technique allows the generation of quantitative results. This is crucial, as $P$. jiroveci may be present in low quantities in some asymptomatic individuals (Maskell et al., 2003; Nevez et al., 2001). Consequently, it is of utmost importance to be able to discriminate between asymptomatic carriership and clinically relevant infection. In recent years, molecular tests to detect $P$. jiroveci have shifted from research to diagnostic applications (Flori et al., 2004; Larsen et al., 2004; Olsson et al., 2001). Nevertheless, quality control panels for validation and standardization of such tests are currently lacking. Therefore, a study was initiated to compare the performance of three independently developed real-time PCR assays for the detection of $P$. jiroveci in three different tertiary care centres in The Netherlands. This retrospective study assessed the routine diagnostic performance of these assays on a collection of BAL fluid samples of which the microscopic evaluation for the presence of $P$. jiroveci had already been performed.

\section{METHODS}

Design of the study. Three diagnostic medical microbiology laboratories participated in this study, i.e. Maastricht Infection Center (MINC), Radboud University Nijmegen Medical Center (RUNMC) and Leiden University Medical Center (LUMC). All three laboratories are university tertiary care centres located in the Netherlands. Each of these laboratories supplied $P$. jiroveci-positive and -negative samples. Diagnosis was based on microscopy. The materials were collected by one of the authors (C. F. M. Linssen), encoded, and distributed to the other laboratories. Each laboratory received a set of samples and performed its own real-time PCR in a blinded fashion.

BAL fluid sampling and conventional diagnosis of PCP. Samples obtained from patients suspected of PCP were collected over the period August 1999 to April 2004. Bronchoscopy with BAL was performed with sterile saline, in four aliquots of $50 \mathrm{ml}$ (MINC), three aliquots of $20 \mathrm{ml}$ (LUMC) and three aliquots of $50 \mathrm{ml}$ (RUNMC). Samples were immediately transported to the laboratory and processed upon arrival. At the LUMC and RUNMC, aliquots of $10 \mathrm{ml}$ were centrifuged at $3000 \mathrm{~g}$ and smears were made from the sediment. At the MINC, cytocentrifuged monolayer preparations were made as previously described (Jacobs et al., 2001). Subsequently, slides were subjected to Giemsa and methenamine silver staining (LUMC), Giemsa and direct immunofluorescence staining (PneumoCel, CeLLabs) (RUNMC), or May-Grünwald Giemsa and methenamine silver staining (MINC).

Nucleic acid extraction and real-time PCR analysis. At the MINC, $200 \mu \mathrm{l}$ BAL fluid was used for DNA isolation using the Wizard Genomic DNA Purification kit (Promega). Purified DNA was resuspended in a final volume of $120 \mu \mathrm{l}$. A real-time PCR was designed that targeted the major surface glycoprotein (MSG) gene (Larsen et al., 2002a). Assays were performed in 96-well Optical Reaction plates [Applied Biosystems (ABI)] in a $50 \mu \mathrm{l}$ volume containing $0.6 \mu \mathrm{M}$ each of primers PCPFor and PCPRev (Table 1), $0.15 \mu \mathrm{M}$ probe PCPProbe, $1 \times$ TaqMan Universal Master Mix (ABI) and $20 \mu \mathrm{l}$ purified DNA. Thermal cycling was carried out on an ABI PRISM 7000 Sequence Detection system (ABI) as follows: 2 min at $50{ }^{\circ} \mathrm{C}, 10 \mathrm{~min}$ at $95^{\circ} \mathrm{C}$, followed by 42 cycles of $15 \mathrm{~s}$ at $95^{\circ} \mathrm{C}$ and $1 \mathrm{~min}$ at $60^{\circ} \mathrm{C}$. Quantification was performed using the ABI PRISM software and was based on extrapolation of data to standard curves, which were generated by amplification of quantified dilutions of the plasmid pPCP, which contains the P. jiroveci PCR fragment.

At the RUNMC, the MagnaPure LC Isolation station (Roche Applied Science) was used for nucleic acid isolation. A $100 \mu$ l aliquot was isolated using the Total Nucleic Acid isolation kit (Roche Applied Science). Nucleic acids were resuspended in $50 \mu \mathrm{H}_{2} \mathrm{O}$. Real-time PCR for $P$. jiroveci was performed as described by Larsen et al. (2002a) using the MSG gene as target. All reactions were performed in a volume of $20 \mu \mathrm{l}$, consisting of $1 \times$ LightCycler FastStart DNA Master

Table 1. Description of primers and probes used by the three laboratories

The sequences for primers and probes used by MINC and RUNMC were obtained from Larsen et al. (2002).

\begin{tabular}{|c|c|c|c|c|c|}
\hline Laboratory & Target & $\begin{array}{l}\text { Primer } \\
\text { type }\end{array}$ & Sequence $\left(5^{\prime}-3^{\prime}\right)$ (name) & $\begin{array}{c}\text { GenBank } \\
\text { accession no. }\end{array}$ & $\begin{array}{l}\text { Position } \\
\text { on gene }\end{array}$ \\
\hline \multirow[t]{2}{*}{ MINC } & \multirow[t]{2}{*}{ MSG } & F & CAAAAATAACAYTSACATCAACRAGG (PCPFor) & \multirow[t]{2}{*}{ AF372980 } & $223-248$ \\
\hline & & $\mathrm{R}$ & AAATCATGAACGAAATAACCATTGC (PCPRev) & & $378-354$ \\
\hline \multirow[t]{2}{*}{ LUMC } & \multirow[t]{2}{*}{ DHPS } & $\mathrm{F}$ & ATGATTCTATATTAATGGATGTGGAG (PJIRs) & \multirow[t]{2}{*}{ AJ586567 } & $148-173$ \\
\hline & & $\mathrm{P}$ & MB-CGCGCTGGGCGACGATAATTGATATTGGTGGAGCGCG-FAM (578PJIR) & & $190-214$ \\
\hline \multirow[t]{4}{*}{ RUNMC } & \multirow[t]{4}{*}{ MSG } & $\mathrm{F}$ & GAATGCAAATCYTTACAGACAACA (JKK114/15) & \multirow[t]{4}{*}{ AF37298 } & $135-158$ \\
\hline & & P1 & CAAAAATAACAYTSACATCAACRAGGC (PCMSGFRET1U) & & $223-248$ \\
\hline & & $\mathrm{P} 2$ & TGCAAACCAACCAAGTGTACGACAGG (PCMSGFRET1D) & & $252-277$ \\
\hline & & $\mathrm{R}$ & AAATCATGAACGAAATAACCATTGC (JKK17) & & $378-354$ \\
\hline
\end{tabular}

${ }^{\star} \mathrm{F}$, forward primer; $\mathrm{P}$, probe; $\mathrm{R}$, reverse primer. 
Table 2. Origin of BAL fluid samples included in this study

\begin{tabular}{|c|c|c|c|c|c|}
\hline \multirow{2}{*}{$\begin{array}{l}\text { Microscopy result } \\
\text { for } P \text {. jiroveci }\end{array}$} & \multicolumn{2}{|c|}{ Patients at risk ${ }^{\star}$} & \multicolumn{2}{|c|}{ Patients not at risk } & \multirow[t]{2}{*}{ Total } \\
\hline & $\begin{array}{c}\text { HIV } \\
\text { positive }\end{array}$ & $\begin{array}{c}\text { HIV } \\
\text { negative }\end{array}$ & $\begin{array}{c}\text { Ventilator-associated } \\
\text { pneumonia }\end{array}$ & Sarcoidosis $\dagger$ & \\
\hline Positive & 21 & 20 & 0 & 0 & 41 \\
\hline Negative & 10 & 33 & 20 & 20 & 83 \\
\hline
\end{tabular}

${ }^{\star}$ HIV-infected patients, or patients with a known risk factor for PCP, such as haematological malignancy, bone marrow or organ transplantation, Wegener's granulomatosis, and immunosuppressive or corticosteroid therapy. $\dagger$ Sarcoidosis patients were not receiving immunosuppressive therapy or corticosteroids.

Hybridization Probes reaction mixture (Roche), $4 \mathrm{mM} \mathrm{MgCl}_{2}, 1 \cdot 0 \mu \mathrm{M}$ each of primers JKK14/15 and JKK17 (Table 1), $0 \cdot 2 \mu \mathrm{M}$ each of probes PCMSGFRET1U and PCMSGFRET1D, and $5 \mu$ template. The PCR thermal profile consisted of an initial incubation at $95^{\circ} \mathrm{C}$ for $10 \mathrm{~min}$, followed by a touch-down procedure, consisting of 11 cycles of $5 \mathrm{~s}$ at $95^{\circ} \mathrm{C}$ and $10 \mathrm{~s}$ at temperatures decreasing from 65 to $50^{\circ} \mathrm{C}$. This was followed by 35 cycles of $5 \mathrm{~s}$ at $95^{\circ} \mathrm{C}$ and $10 \mathrm{~s}$ at $50^{\circ} \mathrm{C}$, and a final step of $15 \mathrm{~s}$ at $72^{\circ} \mathrm{C}$. Amplification, detection and data analysis were executed using the LightCycler v2.0 system (Roche).

At the LUMC, nucleic acids were extracted from $200 \mu \mathrm{l}$ samples using the Qiagen whole blood DNA extraction kit (Qiagen). Each sample was eluted using $200 \mu$ l elution buffer. Real-time PCR for P. jiroveci was targeted at the dihydroperoate synthase (DHPS) gene, and was performed in $50 \mu \mathrm{l}$ reaction mixtures, consisting of $1 \times$ HotstarTaq mastermix (Qiagen), $3.5 \mathrm{mM} \mathrm{MgCl}_{2}, 0.4 \mu \mathrm{M}$ each primer, $0.34 \mu \mathrm{M}$ molecular beacon probe and $10 \mu \mathrm{l}$ purified DNA. The PCR thermal profile consisted of $15 \mathrm{~min}$ at $95^{\circ} \mathrm{C}$, followed by 50 cycles of $30 \mathrm{~s}$ at $95^{\circ} \mathrm{C}, 30 \mathrm{~s}$ at $55^{\circ} \mathrm{C}$ and $30 \mathrm{~s}$ at $72^{\circ} \mathrm{C}$. Amplification, detection and data analysis were performed with an iCycler IQ Real-Time Detection system (Bio-Rad).

Additional analyses. Since two of the three PCR assays were based on a multicopy target (MSG) and one assay on a single-copy target (DHPS), comparison of quantification was performed on the basis threshold cycle $\left(C_{t}\right)$ values rather than absolute quantifications. In 26 samples (positive samples from the MINC), the $P$. jiroveci burden was also quantified microscopically (Kovacs et al., 1988). For these samples, microscopic quantification was compared to PCR quantification using the MINC assay (described above).

Statistical analysis. Qualitative inter-assay agreement was assessed by pairwise comparisons of test results from the three laboratories by calculating the crude percentage agreement and the kappa statistic. For this comparison, the results obtained on the initial run for each sample were taken and any $C_{t}$ value obtained was considered as a positive result. Further pairwise correlations between the $C_{t}$ values of the different laboratories for each sample were calculated using the Pearson correlation coefficient. Correlation between microscopy quantification and real-time PCR quantification was also expressed as a correlation coefficient.

\section{RESULTS AND DISCUSSION}

\section{Origin of BAL fluid samples}

A total of 124 BAL fluid samples collected during the period August 1999 to April 2004 were included. They were recovered either from HIV-positive or HIV-negative patients with a known risk factor for PCP, such as (haematological) malignancy, bone marrow or organ transplantation, Wegener's granulomatosis, and immunosuppressive or corticosteroid therapy (Miller, 1999; Thomas et al., 2004). In addition, a number of BAL fluid samples obtained from patients with no known risk factor for PCP were included (Table 2). These samples were obtained from patients with newly diagnosed sarcoidosis or ventilator-associated pneumonia. The samples were obtained form the LUMC $(n=20)$, RUNMC $(n=18)$ and MINC $(n=86)$. As shown in Table 2 , 41 samples $(33 \cdot 1 \%)$ were found to be positive for $P$. jiroveci by microscopy.

\section{Qualitative agreement between the three P. jiroveci real-time PCR assays}

All 124 samples were subjected to real-time PCR at each of the three participating laboratories. For 114 (91.9\%) of the 124 samples, the three laboratories obtained identical qualitative results (Table 3 ). Forty out of $41(97 \cdot 6 \%)$ microscopy-positive samples were found positive in all three PCR assays. The remaining microscopy-positive sample was

Table 3. Comparison of the three real-time PCR assays for the detection of $P$. jiroveci

+ , Positive; - , negative.

\begin{tabular}{|lccc|}
\hline \multirow{2}{*}{ Number of samples } & \multicolumn{3}{c|}{ Real-time PCR result for: } \\
\cline { 2 - 4 } & MINC & LUMC & RUNMC \\
\hline Microscopy-positive & & & \\
samples $(n=41)$ & & & \\
40 & + & + & + \\
1 & + & - & - \\
Microscopy-negative & & & \\
samples $(n=83)$ & & & - \\
69 & - & - & + \\
5 & + & + & + \\
4 & - & - & - \\
2 & + & - & + \\
1 & + & + & - \\
1 & + & - & + \\
1 & - & + & \\
\hline
\end{tabular}


only positive in a single assay, but showed a relatively high $\mathrm{C}_{\mathrm{t}}$ value $(36 \cdot 6)$. This sample was obtained from a patient with a low parasite burden (one cyst in one out of three investigated microscopic slides). This patient had been diagnosed with PCP a week earlier and had been treated with cotrimoxazole during the week previous to the bronchoscopy.

Of the 83 microscopy-negative samples, $69(83 \cdot 1 \%)$ were found negative in all three PCR assays (Table 3). The remaining 14 samples were PCR positive in at least one of the three assays. Five of these were positive in all three assays, two samples were positive in two of the assays, and seven samples were positive in a single assay only. The majority (12/14) of the patients with microscopy-negative/PCRpositive results were HIV-negative patients with one or more risk factors for PCP (data not shown). An additional patient was HIV-positive, and the remaining patient did not have any known risk factors. The most likely explanation for the microscopy-negative/PCR-positive results is the higher sensitivity of PCR in comparison with microscopy.

The agreement between the three $P$. jiroveci real-time PCR assays was assessed by pairwise comparisons of the qualitative test results. The highest agreement was found between the MINC and LUMC assays, with a percentage agreement of $96.8 \%$ and a kappa value of 0.93 . The agreement between the other assays was also excellent, with a percentage agreement of $94 \cdot 4 \%$ and a kappa value of $0 \cdot 88$, both between the MINC and RUNMC assays and between the RUNMC and LUMC assays.

\section{Quantitative comparison between the three real-time PCR assays}

To compare the quantitative performance of the three realtime PCR assays, pairwise correlations between $C_{t}$ values generated on samples that were scored positive in all three assays ( $n=45$; Table 3 ) were calculated. As shown in Fig. 1, there was a good correlation between the $\mathrm{C}_{t}$ values produced by each of the three assays. The correlation coefficients were $0.84,0.90$ and 0.99 between the LUMC and MINC assays, the MINC and RUNMC assays, and the LUMC and RUNMC assays, respectively. While the RUNMC and LUMC assays generated similar $C_{t}$ values (Fig. 1a), the $C_{t}$ values produced by the MINC assay were somewhat lower than those produced by the other assays (Fig. 1a, c).

\section{Quantitative comparison between microscopy and real-time PCR}

To examine the correlation between microscopy and realtime PCR in quantitative detection, the results from these assays were compared for a selection of positive samples $(n=26)$. Since a comparison with $C_{t}$ values might be difficult to interpret, these values were first converted to copy-number equivalents of a plasmid (pPCP) containing the $P$. jiroveci amplicon. This was achieved in the MINC realtime PCR assay by generating a standard curve using this
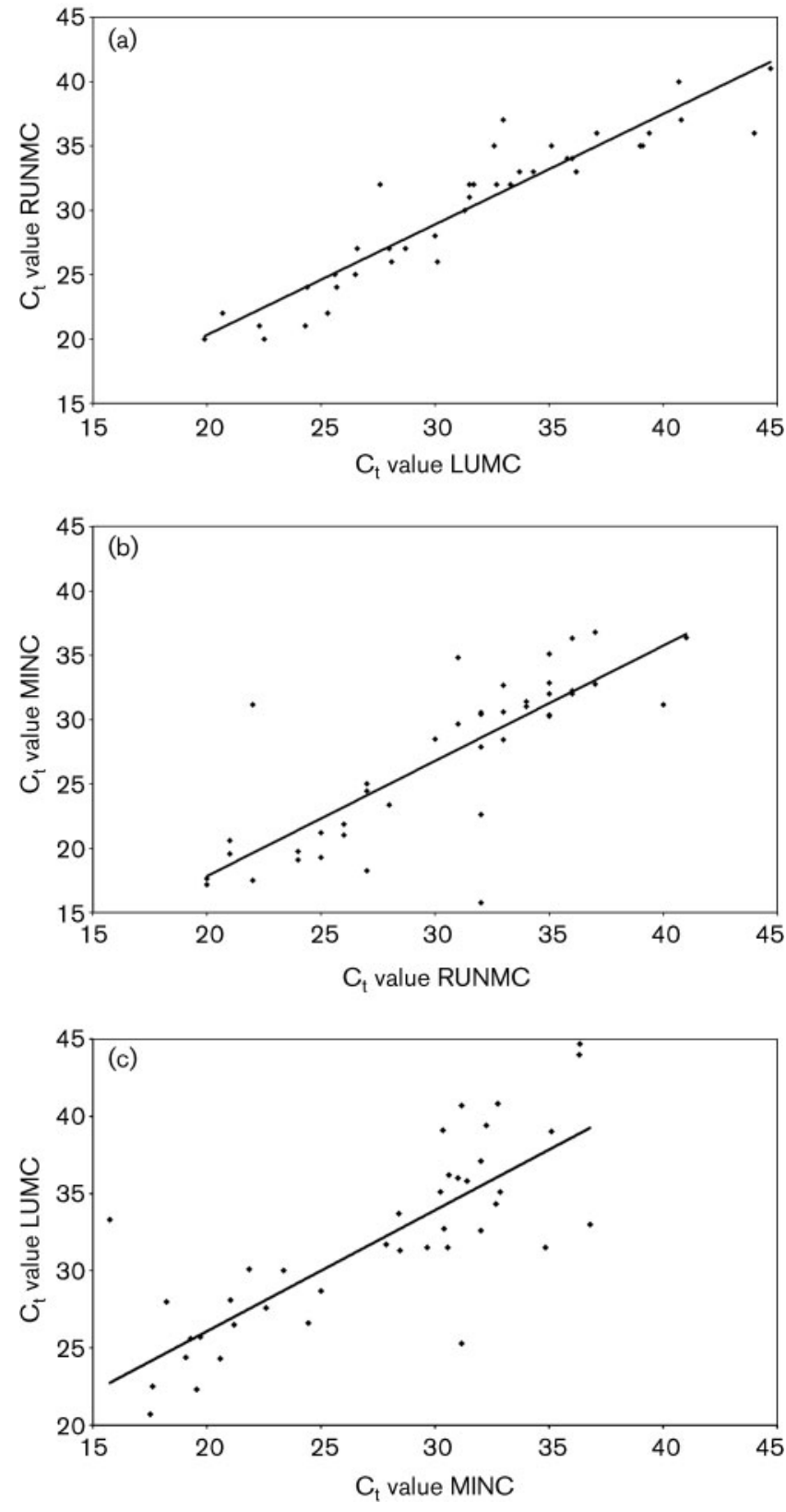

Fig. 1. Pairwise comparison between the different $C_{t}$ values for all samples $(n=45)$ that were found to be positive in all three real-time PCR assays. (a) Comparison of $C_{t}$ values from the RUNMC assay ( $y$ axis) and the LUMC assay ( $x$ axis); (b) comparison of the $C_{t}$ values from the MINC assay ( $y$ axis) and the RUNMC assay ( $x$ axis); (c) comparison of the $C_{t}$ values from the LUMC assay ( $y$ axis) and the MINC assay ( $x$ axis).

plasmid (Fig. 2a, b). Subsequently, the copy-number equivalents of the $26 \mathrm{P}$. jiroveci-positive samples were plotted against the microscopically quantified $P$. jiroveci burden (expressed as clusters per cytospin spot). As shown in Fig. 2(c), there was a good correlation between both methods, which was expressed as a correlation coefficient of $0 \cdot 83$. 


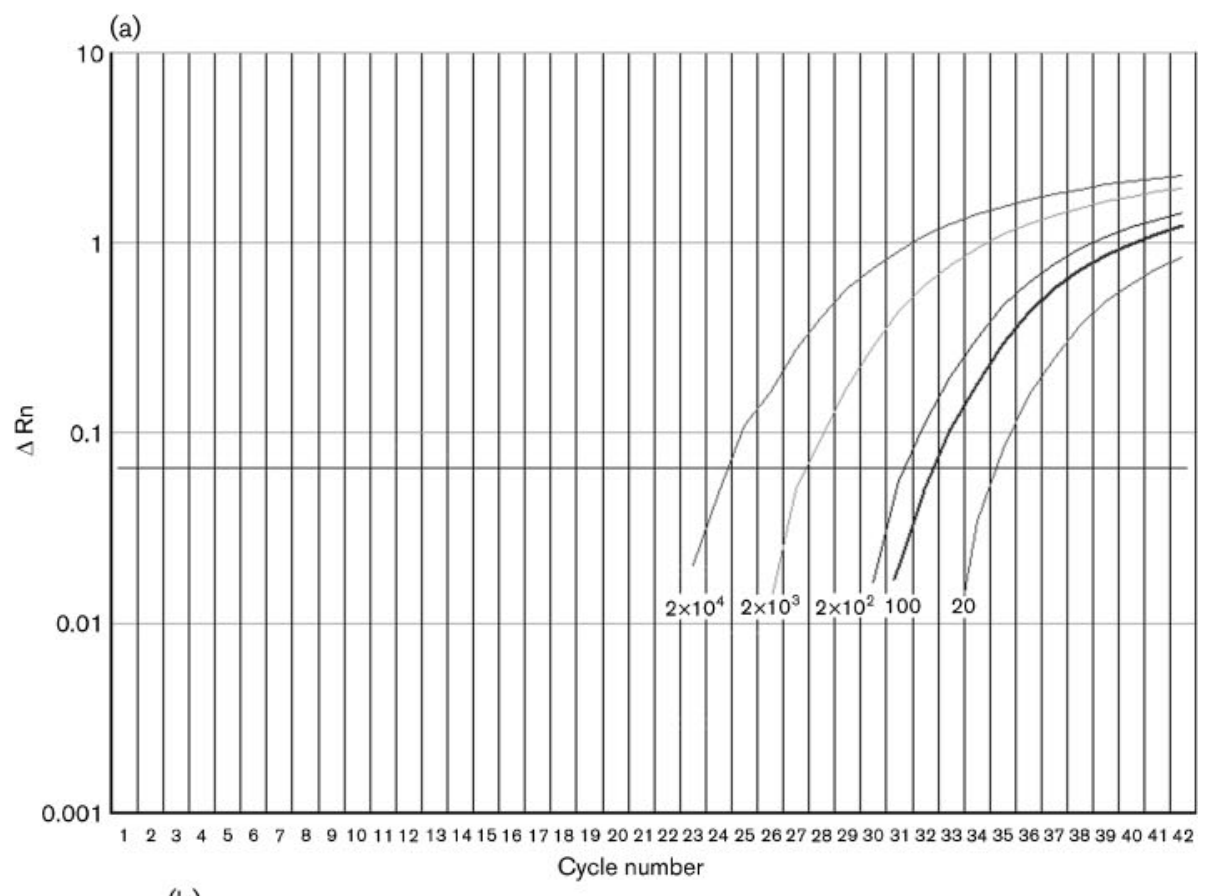

(b)

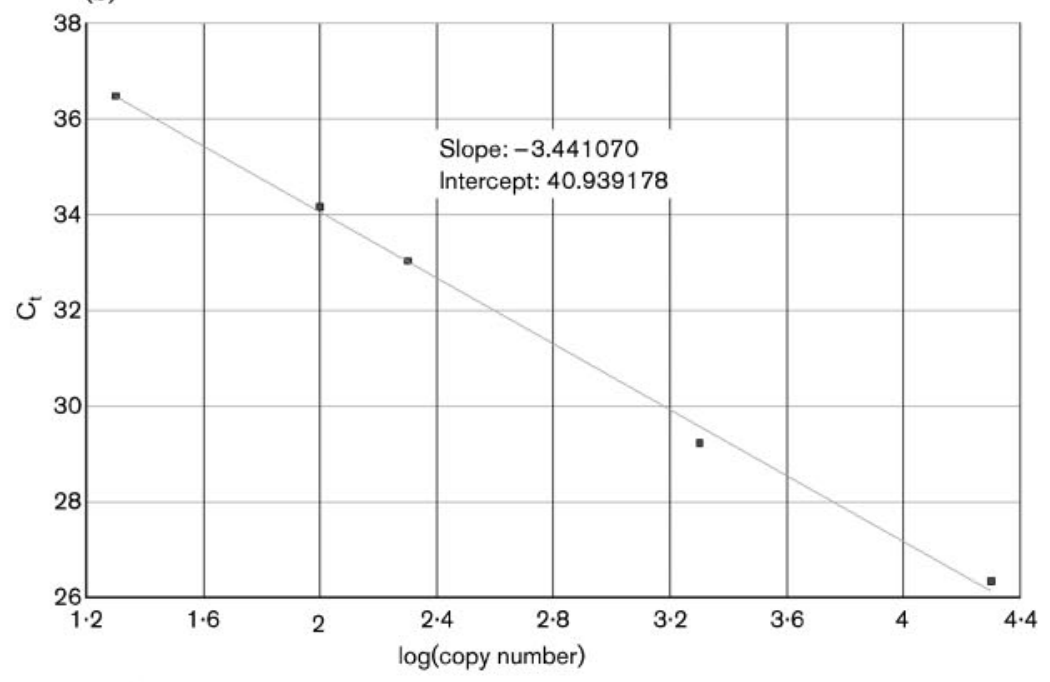

(c)

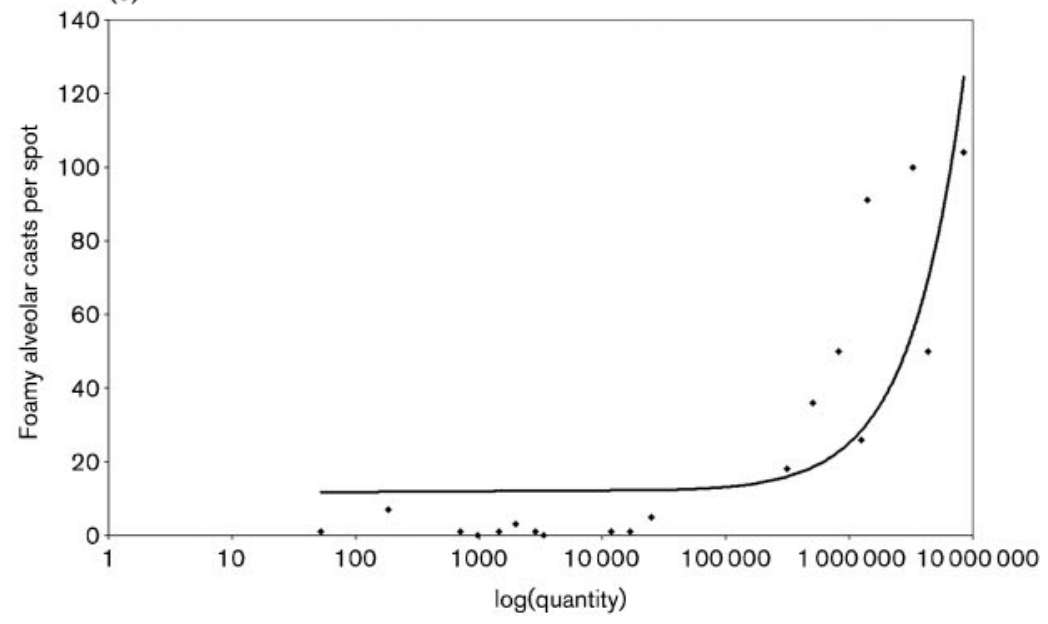

Fig. 2. Correlation between microscopy and the MINC real-time PCR assay in quantification of $P$. jiroveci. (a) Amplification plot $(\Delta \mathrm{Rn}$ versus cycle number) generated with dilutions of plasmid pPCP $\left(2 \times 10^{4}, 2 \times 10^{3}\right.$, $2 \times 10^{2}, 100$ and 20 copies per reaction), which contains the $P$. jiroveci amplicon. (b) Standard curve $\left[C_{t}\right.$ versus log(copy number)] generated from the amplification plot shown in (a). (c) Correlation between the number of $P$. jiroveci clusters per cytospin spot (foamy alveolar casts per spot) and the log of the $P$. jiroveci copy number [log(quantity)] for 26 PCR-positive BAL fluid samples. 


\section{P. jiroveci carriership versus clinically relevant infection}

An important issue in the diagnosis of PCP is the distinction between apparent asymptomatic $P$. jiroveci carriers and patients with clinically obvious PCP. In most studies, carriers have been defined as patients in whom $P$. jiroveci DNA can be detected in the absence of clinical signs of $P$. jiroveci infection, and without microscopically detectable $P$. jiroveci cysts in BAL fluid samples. In the present study, we found an overlap between $C_{t}$ values in samples obtained from potential carriers of $P$. jiroveci on the one hand and some of the samples from patients with clinically and microscopically proven PCP on the other. This is in line with earlier reports, in which a reliable cut-off value for the differentiation between disease and carrier states could not be firmly established (Flori et al., 2004; Larsen et al., 2004). Nevertheless, it is possible to divide patients into three categories. The first category includes patients with clinical symptoms indicative of PCP, and with a positive PCR result and/or a positive microscopy result; these patients are diagnosed with PCP. The second category includes patients who have no clinical symptoms and do not have any indication of infection with $P$. jiroveci, as indicated by negative results in both microscopy and PCR. The third group is more complex, and consists of patients who do not have typical clinical symptoms of PCP, but show a positive PCR result (usually with high $C_{t}$ values). We hypothesize that the patients without risk factors for PCP should be regarded as asymptomatic carriers and do not require treatment for PCP. In the case of patients belonging to the at-risk group with negative microscopy results, the microscopy should be re-evaluated and the patient should be followed clinically and receive therapy at the appearance of any clinical symptoms indicative of PCP.

Previously, only immunocompromised patients, such as HIV-positive patients, were considered to be potential carriers of $P$. jiroveci (Weig et al., 1996, 1997). More recently, however, immunocompetent individuals have also been found to be putative carriers (Sing et al., 1999; Visconti et al., 2000). Miller and coworkers investigated health-care workers who had come into contact with patients with PCP and found among them a carrier rate of $30 \cdot 5 \%$ (Miller, 1999). In particular, health-care workers taking BAL or induced sputum samples were found to be at risk of developing a carrier status, which in one case persisted for 27 months (Miller et al., 2001). All P. jiroveci-DNA-positive patients from our study belonged to the group at risk, except for a single patient who was admitted to the intensive care unit and diagnosed with a community-acquired pneumonia caused by Streptococcus pneumoniae.

In conclusion, we have compared the performance of three different in-house-developed real-time PCR assays for $P$. jiroveci. Interestingly, while these three assays employ different methods for nucleic acid isolation, amplification and detection, an excellent agreement in performance was found between the assays, both qualitatively (the diagnosis of PCP) and quantitatively (the P. jiroveci burden). Likewise, a good correlation was found between the $P$. jiroveci quantities determined by real-time PCR and microscopic quantification. A cut-off value to discriminate between disease and carrier status for $P$. jiroveci could not be established in the present retrospective study. A future prospective study is needed to investigate whether quantitative PCR results can be employed to differentiate between PCP and carriership of $P$. jiroveci. Finally, in order to monitor the performance of the different in-house PCR assays currently used in microbiology laboratories, the availability of quality control panels is of utmost importance. The assays described here could serve as reference assays in the development and maintenance of such panels.

\section{ACKNOWLEDGEMENTS}

C. V. is supported by a fellowship from the Royal Netherlands Academy of Arts and Sciences (KNAW).

\section{REFERENCES}

Amin, M. B., Mezger, E. \& Zarbo, R. J. (1992). Detection of Pneumocystis carinii. Comparative study of monoclonal antibody and silver staining. Am J Clin Pathol 98, 13-18.

Chandra, P., Delaney, M. D. \& Tuazon, C. U. (1988). Role of special stains in the diagnosis of Pneumocystis carinii infection from bronchial washing specimens in patients with the acquired immune deficiency syndrome. Acta Cytol 32, 105-108.

Djamin, R. S., Drent, M., Schreurs, A. J., Groen, E. A. \& Wagenaar, S. S. (1998). Diagnosis of Pneumocystis carinii pneumonia in HIVpositive patients. Bronchoalveolar lavage vs. bronchial brushing. Acta Cytol 42, 933-938.

Edman, J. C., Kovacs, J. A., Masur, H., Santi, D., Elwood, V. H. J. \& Sogin, M. L. (1988). Ribosomal RNA sequence shows Pneumocystis carinii to be a member of the fungi. Nature 334, 519-522.

Elvin, K. M., Bjorkman, A., Linder, E., Heurlin, N. \& Hjerpe, A. (1988). Pneumocystis carinii pneumonia: detection of parasites in sputum and bronchoalveolar lavage fluid by monoclonal antibodies. BMJ 297, 381-384.

Flori, P., Bellete, B., Durand, F., Raberin, H., Cazorla, C., Hafid, J., Lucht, F. \& Sung, R. T. (2004). Comparison between real-time PCR, conventional PCR and different staining techniques for diagnosing Pneumocystis jiroveci pneumonia from bronchoalveolar lavage specimens. J Med Microbiol 53, 603-607.

Jacobs, J. A., Dieleman, M. M., Cornelissen, E. I., Groen, E. A., Wagenaar, S. S. \& Drent, M. (2001). Bronchoalveolar lavage fluid cytology in patients with Pneumocystis carinii pneumonia. Acta Cytol 45, 317-326.

Kovacs, J. A., Ng, V. L., Masur, H. \& 7 other authors. (1988). Diagnosis of Pneumocystis carinii pneumonia: improved detection in sputum with use of monoclonal antibodies. $N$ Engl J Med 318, 589-593.

Kovacs, J. A., Gill, V. J., Meshnick, S. \& Masur, H. (2001). New insights into transmission, diagnosis, and drug treatment of Pneumocystis carinii pneumonia. JAMA (J Am Med Assoc) 286, 2450-2460.

Larsen, H. H., Kovacs, J. A. F., Stock, F., Vestereng, V. H., Lundgren, B., Fischer, S. H. \& Gill, V. J. (2002a). Development of a rapid real-time PCR assay for quantitation of Pneumocystis carinii f. sp. carinii. J Clin Microbiol 40, 2989-2993. 
Larsen, H. H., Masur, H., Kovacs, J. A. \& 7 other authors (2002b). Development and evaluation of a quantitative, touch-down, realtime PCR assay for diagnosing Pneumocystis carinii pneumonia. J Clin Microbiol 40, 490-494.

Larsen, H. H., Huang, L., Kovacs, J. A. \& 7 other authors (2004). A prospective, blinded study of quantitative touch-down polymerase chain reaction using oral-wash samples for diagnosis of Pneumocystis pneumonia in HIV-infected patients. J Infect Dis 189, 1679-1683.

Limper, A. H., Offord, K. P., Smith, T. F. \& Martin, W. J., 2nd (1989). Pneumocystis carinii pneumonia. Differences in lung parasite number and inflammation in patients with and without AIDS. Am Rev Respir Dis 140, 1204-1209.

Maskell, N. A., Waine, D. J., Lindley, A., Pepperell, J. C., Wakefield, A. E., Miller, R. F. \& Davies, R. J. (2003). Asymptomatic carriage of Pneumocystis jiroveci in subjects undergoing bronchoscopy: a prospective study. Thorax 58, 594-597.

Miller, R. F. (1999). Pneumocystis carinii infection in non-AIDS patients. Curr Opin Infect Dis 12, 371-377.

Miller, R. F., Ambrose, H. E. \& Wakefield, A. E. (2001). Pneumocystis carinii f. sp. hominis DNA in immunocompetent health care workers in contact with patients with P. carinii pneumonia. J Clin Microbiol 39, 3877-3882.

Nevez, G., Guyot, K., Totet, A., Raccurt, C. \& Dei-Cas, C. (2001). Pulmonary colonisation with Pneumocystis carinii in an immunosuppressed HIV-negative patient: detection and typing of the fungus by PCR. J Med Microbiol 50, 198-200.

Olsson, M., Stralin, K. \& Holmberg, H. (2001). Clinical significance of nested polymerase chain reaction and immunofluorescence for detection of Pneumocystis carinii pneumonia. Clin Microbiol Infect 7, 492-497.
Sepkowitz, K. A. (2002). Opportunistic infections in patients with and patients without Acquired Immunodeficiency Syndrome. Clin Infect Dis 34, 1098-1107.

Sing, A., Roggenkamp, A., Autenrieth, I. B. \& Heesemann, J. (1999). Pneumocystis carinii carriage in immunocompetent patients with primary pulmonary disorders as detected by single or nested PCR. J Clin Microbiol 37, 3409-3410.

Stringer, J. R., Cushion, M. T. \& Wakefield, A. E. (2001). New nomenclature for the genus Pneumocystis. J Eukaryot Microbiol Suppl., 184S-189S.

Thomas, C. F., Jr \& Limper, A. H. (2004). Pneumocystis pneumonia. $N$ Engl J Med 350, 2487-2498.

Visconti, E., Marinaci, S., Zolfo, M., Mencarini, P., Tamburrini, E., Pagliari, G., Ortona, E. \& Siracusano, A. (2000). Very low frequence of Pneumocystis carinii DNA detection by PCR in specimens from patients with lung damage. J Clin Microbiol 38, 1307-1308.

Wakefield, A. E., Pixley, F. J., Banerji, S., Sinclair, K., Miller, R. F., Moxon, E. R. \& Hopkin, J. M. (1990). Detection of Pneumocystis carinii with DNA amplification. Lancet 336, 451-453.

Weig, M., Klinker, H., Wilhelm, M., Lemmer, K. \& Gross, U. (1996). Correlation of Pneumocystis carinii PCR with clinical diagnosis in immunocompromised patients. Lancet 347, 1266.

Weig, M., Klinker, H., Bogner, B. H., Meier, A. \& Gross, U. (1997) Usefulness of PCR for diagnosis of Pneumocystis carinii pneumonia in different patient groups. J Clin Microbiol 35, 1445-1449.

Yale, S. H. \& Limper, A. H. (1996). Pneumocystis carinii pneumonia in patients without acquired immunodeficiency syndrome: associated illness and prior corticosteroid therapy. Mayo Clin Proc 71, 5-13. 